OPEN ACCESS

Edited by:

Miao He,

Fudan University, China

Reviewed by:

Chaoran Ren,

Jinan University, China

Yiran Gu,

East China Normal University, China

${ }^{*}$ Correspondence:

Han Xu

xuhan2014@zju.edu.cn

Specialty section:

This article was submitted to

Non-Neuronal Cells,

a section of the journal

Frontiers in Cellular Neuroscience

Received: 30 September 2020

Accepted: 27 November 2020

Published: 17 December 2020

Citation:

Wang J, Tian Y, Zeng L-H and Xu H (2020) Prefrontal Disinhibition in Social Fear: A Vital Action of

Somatostatin Interneurons.

Front. Cell. Neurosci. 14:611732. doi: 10.3389/fncel.2020.611732

\section{Prefrontal Disinhibition in Social Fear: A Vital Action of Somatostatin Interneurons}

\author{
Jun Wang ${ }^{1,2}$, Yuanyuan Tian ${ }^{1,2}$, Ling-Hui Zeng ${ }^{3}$ and Han $\mathrm{X} u^{1,2,3 *}$ \\ 'Department of Neurobiology and Department of Neurology of the Second Affiliated Hospital, Zhejiang University School of \\ Medicine, Hangzhou, China, ${ }^{2}$ NHC and CAMS Key Laboratory of Medical Neurobiology, MOE Frontier Science Center for \\ Brain Research and Brain-Machine Integration, School of Brain Science and Brain Medicine, Zhejiang University, Hangzhou, \\ China, ${ }^{3}$ Department of Pharmacology, School of Medicine, Zhejiang University City College, Hangzhou, China
}

Social fear and avoidance of social partners and social situations represent the core behavioral symptom of Social Anxiety Disorder (SAD), a prevalent psychiatric disorder worldwide. The pathological mechanism of SAD remains elusive and there are no specific and satisfactory therapeutic options currently available. With the development of appropriate animal models, growing studies start to unravel neuronal circuit mechanisms underlying social fear, and underscore a fundamental role of the prefrontal cortex (PFC). Prefrontal cortical functions are implemented by a finely wired microcircuit composed of excitatory principal neurons (PNs) and diverse subtypes of inhibitory interneurons (INs). Disinhibition, defined as a break in inhibition via interactions between IN subtypes that enhances the output of excitatory PNs, has recently been discovered to serve as an efficient strategy in cortical information processing. Here, we review the rodent animal models of social fear, the prefrontal IN diversity, and their circuits with a particular emphasis on a novel disinhibitory microcircuit mediated by somatostatin-expressing INs in gating social fear behavior. The INs subtype distinct and microcircuit-based mechanism advances our understanding of the etiology of social fear and sheds light on developing future treatment of neuropsychiatric disorders associated with social fear.

Keywords: social anxiety disorder, social fear, interneuron, disinhibition, prefrontal cortex

\section{INTRODUCTION}

The fear response to an imminent threat is an adaptive behavior and is essential to avoid danger in the environment for animals and humans. However, persistent and unnecessary fear response represents a maladaptive behavior evident in a large number of psychiatric diseases such as posttraumatic stress disorder (PTSD) and anxiety disorders (Buff et al., 2016; Nees et al., 2018). Intense and persistent fear and avoidance of social situations represent the core behavioral symptom of social anxiety disorder (SAD), a prevalent psychiatric disorder worldwide (Kessler et al., 2005a,b; Stein and Stein, 2008; Leichsenring and Leweke, 2017). Social fear makes even the simplest daily task challenging and distressful and literally disconnects individuals afflicted from others and society. Unfortunately, there are no satisfactory therapeutic options currently available (Stein and Stein, 2008; Dos Santos et al., 2019). The pathological mechanism underlying SAD is undetermined partly due to a lack of specific animal models (Toth et al., 2012, 2013; Toth and Neumann, 2013). Recently, thanks to the effort of several groups of researchers, a couple of experimental paradigms have been 
developed to induce social fear in rodents. Importantly, these paradigms reliably induce robust behavioral changes recapitulating core behavioral symptoms of SAD in humans, without affecting non-social behaviors such as locomotion, general anxiety, and depressive-like behaviors (Toth et al., 2012; Toth and Neumann, 2013; Franklin et al., 2017; Xu et al., 2019). Notably, by using these rodent animal models, neuroscientists start to dissect the neuronal circuit substrates underlying social fear (Franklin et al., 2017; Xu et al., 2019).

Accumulating evidence from human functional brain imaging studies suggests that the prefrontal cortex (PFC) contributes essentially to the processes of social fear responses (Buff et al., 2016; Kawashima et al., 2016). The PFC is composed of a majority of principal neurons (PNs) and a minority of inhibitory interneurons (INs) which exhibit remarkable diversity in morphology, physiological properties, immunohistochemical characteristics, and connectivity (Kawaguchi and Kubota, 1997; Rudy et al., 2011; Xu et al., 2013; Hattori et al., 2017). Different subtypes of INs could effectively control cortical network activity via feedforward, feedback inhibition, and disinhibition (Xu et al., 2013, 2019; Tremblay et al., 2016). Both human and animal studies found that an exquisite balance between excitation and inhibition plays a fundamental role in cortical functions (Rubenstein and Merzenich, 2003; Yizhar et al., 2011; Sohal and Rubenstein, 2019). Moreover, the exact activity patterns of specific prefrontal IN subtypes and their precise microcircuit mechanism in fear-related behaviors including social fear start to emerge (Xu et al., 2019; Cummings and Clem, 2020).

In this review, we will first briefly introduce SAD and summarize major attempts in developing proper experimental paradigms to induce social fear in rodents. Then, we will discuss studies in the exploration of pathological mechanisms underlying social fear by using these rodent animal models. Given the complexity and multidimensional nature of social fear behavior, we will focus our discussion on the brain region of PFC. In specific, we will discuss prefrontal IN diversity and their microcircuits in the context of social fear regulation. Particularly, we will highlight a newly discovered disinhibitory microcircuit in the PFC via interactions between subtypes of INs. We suggest that prefrontal disinhibition mediated by somatostatinexpressing $\left(\mathrm{SST}^{+}\right)$INs represents an essential circuit mechanism in the regulation of social fear behavior.

\section{SOCIAL FEAR AND ANIMAL MODELS OF SOCIAL FEAR}

SAD, also known as social phobia, is one of the most frequent psychiatric illness, with a worldwide lifetime prevalence of up to 13\% (Kessler et al., 2005a,b; Stein and Stein, 2008; Leichsenring and Leweke, 2017), and is more prevalent in adolescents than in adults (Stein and Stein, 2008; Leichsenring and Leweke, 2017). SAD is essentially characterized by persistent avoidance, anxiety, or fear of social or performance situations (Stein and Stein, 2008; Leichsenring and Leweke, 2017). Indeed, social fear and social avoidance is the core behavioral symptom of $\mathrm{SAD}$ in clinical diagnosis. In addition to SAD, social fear or avoidance of social situations is also commonly observed in many other neuropsychiatric disorders, such as autism, schizophrenia, and depression (Jones et al., 2017). Social fear leads to low self-esteem and disconnects individuals from others and society to a varying degree and can cause devastating consequences on the individuals' daily life. Besides, it also causes high social and medical costs to the families afflicted and the society (American Psychiatric Publishing, 2013). Current treatments involve psychotherapy, pharmacotherapy, or a combination of both. These treatment options are effective for some individuals suffering from the disorder. However, the problem is that only partial remission of symptoms can be achieved and the recurrence rate after discontinuation of treatments is high (Blanco et al., 2002). What is even worse, for up to $30-40 \%$ of patients, these exiting treatments do not work (Blanco et al., 2002; Leichsenring and Leweke, 2017). Essentially, a deeper understanding of the pathological mechanisms underlying SAD is urgently needed.

Animal models offer valuable tools for understanding the biological mechanisms involved and finding more effective therapeutic targets for many diseases. However, it has not been successful in developing appropriate animal models for SAD. It has been shown that social fear and social avoidance could be reliably induced with several experimental paradigms, including social conflict (Huhman, 2006), foot shock (Haller and Bakos, 2002), social isolation (Hermes et al., 2011), and maternal separation (Niwa et al., 2011; for review, Toth and Neumann, 2013). Unfortunately, none of these paradigms produced behavioral outcomes that are specified in the social domain. Instead, other phenotypical changes were also evident in these experimental animal models, such as alterations in general anxiety, locomotor functions, as well as depressive-like behaviors (Toth and Neumann, 2013). Therefore, more specific animal models with no confounding factors are required to probe the underlying substrates of social fear. Such animal models are also useful for screening drugs for psychiatric disorders associated with social fear.

To develop rodent models of social fear with more specificity, a couple of elegant studies have recently been conducted by making use of either social fear conditioning (SFC) or sub-chronic social defeat (Figure 1). The SFC paradigm was first introduced by Toth et al. (2012, 2013), which is based on the principle of operant fear conditioning by paring a conspecific social investigation with physical punishment (an electric foot shock). On the conditioning day, the experimental mouse was allowed to acclimate to the conditioning chamber with a floor consisting of a stainless-steel grid that delivers electric foot shocks and an empty wire mesh cage placed near a wall of the chamber. Then an unfamiliar conspecific mouse with matched gender was introduced to the wire mesh cage as a social stimulus. The experimental mouse was allowed to freely investigate the stimulus mouse before conditioning, and then an electric foot shock was manually delivered to the conditioned mouse each time when it approached and investigated the social stimulus mouse. After the conditioning, the conditioned mouse showed a dramatic reduction in the time of social investigation to unfamiliar conspecific mouse and other aversive responses toward the stimulus mouse. 
A

\section{Social fear conditioning}

Fear conditioning

Social interaction test

$24 \mathrm{~h}$ after conditioning

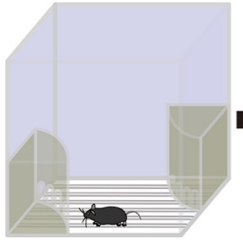

Acclimation

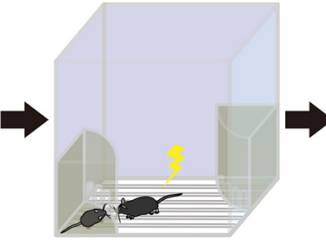

Conditioning

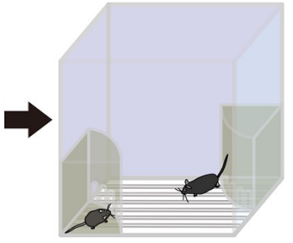

Post-conditioning

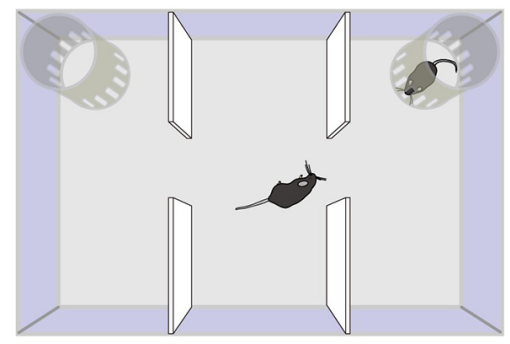

Social interaction test
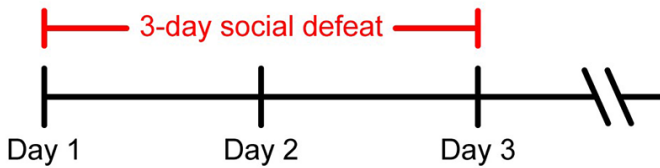

1

Day 10

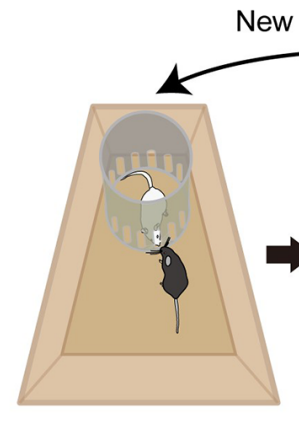

Interaction
New CD1 aggressor (X3 days)

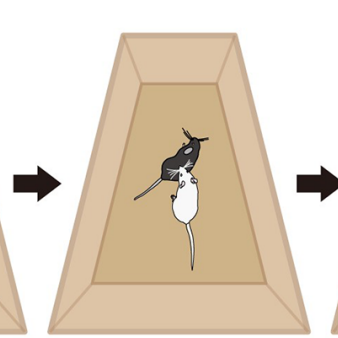

Defeat

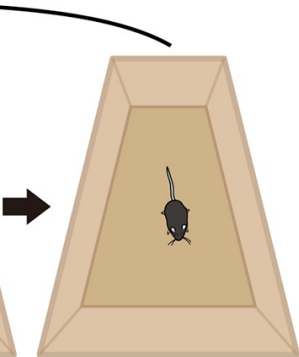

Post-defeat

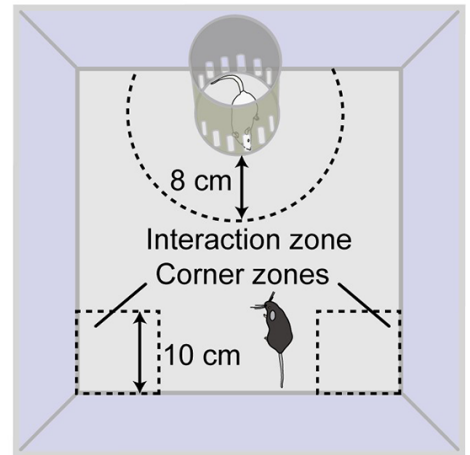

FIGURE 1 | Specific animal models of social fear. (A) Schematic diagram of the social fear conditioning (SFC) paradigm. The experimental mouse was first allowed to acclimate to the conditioning chamber (Acclimation) and then a stimulus mouse was introduced to one of the stimulus cages placed on opposing corners of the conditioning chamber. During the conditioning session, the experimental mouse was allowed to freely interact with the stimulus mouse, while a foot shock was delivered each time when it approached and investigated the stimulus mouse (Conditioning). After conditioning, the procedure was extended to a longer duration to reinforce behavioral adaption (Post-conditioning). Adapted from Xu et al. (2019). (B) Schematic diagram of sub-chronic social defeat paradigm. For three consecutive days, an unfamiliar aggressive male CD1 intruder mouse (white color) was introduced to the home cage of singly-housed adult C57BL/6J male mice (black color). The intruder was confined within a Plexiglas stimulus cage $(10 \mathrm{~cm}$ in diameter) for the first $5 \mathrm{~min}$ (interaction) and then was allowed to attack the experimental mouse for $10 \mathrm{~min}$ (defeat) and withdraw immediately after social confrontations (post-defeat). After 1 week recovery, the expression of social fear to an unfamiliar CD1 mouse was detected in an open field. Social avoidance was assessed by relative time spent in the interaction zone to corner zones.

These behavioral changes reflect the successful induction of social fear in the conditioned mouse. In contrast to previous paradigms, the social fear mouse induced by the SFC paradigm showed no alterations in locomotion, general anxiety, or depressive-like behavior. Therefore, SFC is a reliable paradigm to induce social fear in mice with good specificity (Toth et al., 2012).

In a more recent study by us (Xu et al., 2019), we adopted the conditioning paradigm pioneered by Toth et al. (2012) and made several significant improvements. First, to ensure consistency of conditioning criteria and to reduce the behavioral variation among conditioned subjects, social contacts were monitored, and electric foot shocks were delivered automatically with a computerized conditioning unit equipped with a video tracking system. Second, to ensure fear acquisition specifically to the stimulus mouse but not to the cage, two identical cages were placed at each of two opposing corners of the conditioning unit with one containing a stimulus mouse and the other remaining empty during the conditioning procedure. Third, to reinforce behavioral adaptation of the conditioned mouse, the conditioning procedure was extended to a longer duration $(20 \mathrm{~min})$ although the experimental mice usually did not investigate stimulus mice and thus did not get foot shocks any longer after $5 \mathrm{~min}$. Moreover, we employed C57BL/6J mice for the SFC paradigm instead of CD1 mice or rats by Toth et al. $(2012,2013)$ and therefore extended the application of this conditioning paradigm to a more broadly used species. This extension is important for 
future studies aimed to elucidate the etiology of social fear given that a large number of genetic resources and tools are readily available for $\mathrm{C} 57 \mathrm{BL} / 6 \mathrm{~J}$ mouse lines. Consistent with the findings reported by Toth et al. (2012), the conditioned mice spent significantly less time with the stimulus mouse in a three-chamber social interaction test and exhibited significantly fewer approach times to social stimulus in a social preference-avoidance test. Besides, conditioned mice approached the stimulus mouse in a stretched posture and at a slow speed, two behavioral indicators of an elevated fear state in rodents that were absent in unconditioned control animals. Therefore, our modified conditioning paradigm is robust and reliable. Importantly, conditioned mice behaved normally in response to a novel object and exhibited no alterations in locomotion, general anxiety, and depressive-like behaviors, validating the specificity of behavioral changes in the social domain.

We also compared another social fear model that is induced by social defeat (Xu et al., 2019), which is adapted from a previous study conducted by Franklin et al. (2017). Unlike the SFC that relies on an artificial punishment (electric foot shock), social defeat happens in an experimental setting comparable to the mouse's natural environment, that is, exposure to an aggressor. Repeated social defeat is widely employed as a standardized protocol to induce depressive-like behaviors in C57BL/6J mice (Golden et al., 2011). However, there are several significant differences in using social defeat to induce social fear. First, the duration of social defeat is shorter to establish a social fear mouse model than that for a depressive mouse model. The experimental C57BL/6J mice are exposed to agonistic social confrontations with an aggressive CD1 mouse for three consecutive days (Xu et al., 2019) for the social fear mouse model (so it is called sub-chronic social defeat) compared to a couple of weeks for depression (chronic social defeat). Second, to induce social fear an aggressive CD1 mouse is introduced into the home cage of experimental $\mathrm{C} 57 \mathrm{BL} / 6 \mathrm{~J}$ mice and withdrawn immediately after social confrontations. In contrast, to induce depression the C57BL/6J mouse was living in a shared home cage with a CD1 mouse separated by a clear perforated divider (Golden et al., 2011). In this manner, the defeated mouse is subjected to continuous psychological stress from sensory interaction with the aggressor for the entire modeling period which facilitates its behavioral adaptions. As a consequence, after chronic social defeat, some mice exhibit specific depressive-like behaviors (termed "susceptible") and the others have no change (termed "resilient"; Golden et al., 2011). In comparison, the mice subjected to sub-chronic social defeat showed a reduction in social investigations without alterations in locomotion, general anxiety, and depressive-like behaviors (Xu et al., 2019). Note that, for the SFC paradigm, the conditioned mouse develops a tight association between social stimulus and foot shock after SFC, and the animal shows social fear behavior to the stimulus mouse. Similarly, after sub-chronic defeat, the defeated mouse shows submission to the aggressive intruder. Despite the behavioral similarity of these two animal models, it is still an open question whether these defensive behaviors share the same neural circuits or not.

\section{FUNCTIONS OF THE PREFRONTAL CORTEX IN SOCIAL FEAR}

Recent functional brain imaging studies have identified abnormal activities in several brain regions of patients with SAD (Zhu et al., 2017; Doruyter et al., 2018). These brain regions largely belong to the limbic system including the amygdala (Kraus et al., 2018; Figel et al., 2019; Frick et al., 2020), bed nucleus of the stria terminalis (BNST; Figel et al., 2019), and PFC (Buff et al., 2016; Kawashima et al., 2016; Frick et al., 2020). In particular, both near-infrared spectroscopy (Kawashima et al., 2016) and functional magnetic resonance imaging (fMRI) studies (Buff et al., 2016) revealed that hyperactivity of PFC is tightly linked to excessive and long-lasting fear states in patients with SAD. In human, the PFC is mainly composed of four subregions, namely, orbitofrontal cortex (OFC), dorsolateral PFC, ventrolateral PFC, and mPFC (Ko, 2017), which have an important role in the processing of complicated cognitive and executive behaviors (e.g., social behaviors; Amodio and Frith, 2006) as well as emotion (Etkin et al., 2011). Although it is still controversial, emerging evidence suggests that it is anatomically comparable and functional homologous between human and rodent PFC structures (Dalley et al., 2004). The PFC regions in rodents can be categorized into three major subregions: the dorsal part of the medial PFC (dmPFC), ventral part of the medial PFC (vmPFC), and lateral OFC (IOFC; Kamigaki, 2019). Notably, it is clear now that mPFC is closely linked to fear-related behaviors in rodents, albeit with divergent functions of distinct subregions (Amodio and Frith, 2006).

The prelimbic (PrL) PFC neurons have been believed to encode sustained fear response in classic auditory fear conditioning (Burgos-Robles et al., 2009). It has long been demonstrated by in vivo unit recording that neurons in the amygdala elicit potentiated tone responses that correlate with the acquisition of conditioned fear (Quirk et al., 1995; Paré and Collins, 2000), while these neuronal activities last only a few hundred milliseconds and cannot be responsible for sustained fear responses in the auditory fear conditioning paradigm that last tens of seconds, suggesting the long-lasting fear responses should be stored in other brain structures. Using multichannel electrophysiological recordings in behaving rats, Burgos-Robles et al. (2009) revealed that sustained hyperactivity of the PrL neurons in response to the conditioned tone is correlated with freezing behavior suggesting that PrL neurons integrate inputs from the amygdala and other brain structures that form a top-down control of fear (Etkin et al., 2011) and contribute to the sustained fear expression. In support of this hypothesis, Karalis et al. (2016) found that the freezing response elicited by conditioned tone temporally coincided with sustained synchrony of $4-\mathrm{Hz}$ oscillations in prefrontal-amygdala circuits. Contrary to the PrL, substantial evidence indicates that infralimbic (IL) sub-divisions of the mPFC is necessary for the extinction of conditioned fear (Quirk et al., 2006; Wang et al., 2018). Besides, collective evidence supports that OFC, another sub-division of the mPFC, also plays a crucial role in the regulation of 
conditioned fear (Sarlitto et al., 2018) and fear extinction (Rodriguez-Romaguera et al., 2015; Chang et al., 2018; Hsieh and Chang, 2020). However, in contrast to IL, activation of OFC negatively impaired extinction outcome (Rodriguez-Romaguera et al., 2015; Chang et al., 2018; Hsieh and Chang, 2020).

Despite a large amount of evidence supporting the essential function of PFC in conditioned auditory fear, its role in social fear is much less understood. By c-fos staining, our study found that after exposure to a conspecific mouse, the number of c-fos positive cells was increased in PrL but not in IL of mice with conditioned social fear, indicating a tight link between PrL neuronal activity and social fear expression (Xu et al., 2019). Further, pharmacological inhibition of mPFC with GABAa receptor agonist muscimol dramatically reduces social avoidance in mice with social fear elicited by either SFC or social defeat. As a high-order cerebral cortex, mPFC influences sociability by its projection to several brain areas, including the amygdala, hippocampus, and brainstem (Goodson, 2005). Interestingly, social defeat weakens neural functional connectivity between mPFC and periaqueductal gray (PAG), and selective chemogenetic inhibition of mPFC-PAG projection increases social avoidance (Franklin et al., 2017). Moreover, it has been clarified that layer $5 \mathrm{mPFC}$ projection neurons inhibit excitatory inputs to glutamatergic neurons in PAG via presynaptic neuromodulatory mechanisms, and selective inhibition of these PAG neurons reduces social avoidance (Franklin et al., 2017). These observations provide mechanistic insight regarding the prefrontal modulation of social fear by a specific prefrontal projection to PAG.

\section{CORTICAL INS AND MICROCIRCUIT}

In the adult neocortex, the complex circuitry functions rely on a delicate balance between excitation and inhibition (Xu et al., 2013, 2019). Although neocortical INs represent a minority of total cortical neurons (10-20\% in rodents; Kamigaki, 2019; Xu et al., 2019), they exhibit remarkable diversity in morphology, physiological properties, immunohistochemical characteristics, and connectivity (Kawaguchi and Kubota, 1997; Rudy et al., 2011; Xu et al., 2013; Hattori et al., 2017). Recent evidence suggests that neocortical INs can be divided into non-overlapping subgroups that expressing three different biomarkers: parvalbumin (PV, account for $\sim 40 \%$ of total INs), the neuropeptide somatostatin (SST, account for $\sim 30 \%$ of total INs), and the ionotropic serotonin receptor 5HT3a $(5 \mathrm{HT} 3 \mathrm{aR}$, account for $\sim 30 \%$ of total Ins; Rudy et al., 2011; Tremblay et al., 2016). Within 5HT3aRexpressing INs, $\sim 40 \%$ of neurons also expressing vasoactive intestinal peptide (VIP), and the remaining are non-VIP INs (Rudy et al., 2011; Tremblay et al., 2016), which are the third-largest subtype of INs in the neocortex. In addition to PV, SST, and VIP, other biomarkers are often used to label cortical INs, including neuropeptides cholecystokinin (CCK), neuropeptide Y (NPY), and calcium-binding proteins calbindin (CB). However, these markers are expressed in overlapping populations of INs (Tremblay et al., 2016). The heterogeneity of INs is believed to facilitate their ability to perform complex operations.

INs actively gate information flow and sculpt network dynamics in a subtype-specific manner. $\mathrm{PV}^{+}$and $\mathrm{SST}^{+} \mathrm{INs}$ mainly target the perisomatic and distal dendritic regions of postsynaptic excitatory neurons, respectively (Hattori et al., 2017). By contrast to $\mathrm{PV}^{+}$and $\mathrm{SST}^{+} \mathrm{INs} \mathrm{VIP}^{+}$INs mostly disinhibit excitatory neurons through inhibition of $\mathrm{PV}^{+}$and SST $^{+}$INs (Tremblay et al., 2016). The PV INs can be further divided into fast-spiking (FS) basket and chandelier cells according to their morphology. Chandelier cells, also known as axo-axonic neurons due to their synaptic terminals specifically target the axon initial segment of PNs. In contrast, basket cells mostly target the soma and proximal dendrites of PNs and other INs. SST ${ }^{+}$INs also constitute a diverse group and can be divided into Martinotti and non-Martinotti cells based on their different morphology (Tremblay et al., 2016). In the somatosensory cortex, Martinotti cells are mostly located in superficial (layer 2/3, L2/3) and deep (L5/6) layers, while non-Martinotti cells are mainly located in L4. Intriguingly, these two subtypes of $\mathrm{SST}^{+}$INs also differ in terms of connectivity. In comparison to L2/3 Martinotti cells that predominantly target PNs, L4 non-Martinotti cells predominantly target local $\mathrm{PV}^{+} \mathrm{INs}$ and disinhibit PNs (Xu et al., 2013).

Due to their distinct membrane properties and subcellular targeting on postsynaptic cells, it is suggested that distinct subtypes of INs contribute differentially to different cortical rhythmic oscillations. $\mathrm{PV}^{+}$INs have fast kinetics of membrane property and inhibit local PNs at short latency. Also, $\mathrm{PV}^{+} \mathrm{INs}$ target soma and perisomatic compartments of PNs which are essential subcellular regions to generate spikes, and therefore control the spiking output of PNs (Abbas et al., 2018). The nearby neural assemblies fire co-occurring spikes during the intervals of PV firing and follow the cycle of $\mathrm{PV}^{+}$INs' inhibitory inputs, which in turn leads to coherent oscillation in the local network with a high-frequency band (i.e., gamma oscillation; Cardin et al., 2009; Kamigaki, 2019). In contrast, SST $^{+}$INs have slow kinetics of membrane property and target distal dendrites, which can summate and integrate excitatory inputs of postsynaptic cells over a long time scale (Kamigaki, 2019), and maybe suitable for controlling long-range synchrony between neocortex and the sub-cortical or cortical afferents (Abbas et al., 2018). Although synchronized oscillations, particularly in the gamma band, are thought to facilitate information transfer within and across brain areas, their underlying mechanisms, as well as exact roles, remain a matter of debate (Veit et al., 2017). For example, Chen et al. (2017) showed that suppression of SST ${ }^{+}$INs reduces both the spontaneous and visually induced enhancement of low-frequency band (beta) oscillation in the primary visual cortex (V1). In contrast, suppression of $\mathrm{PV}^{+} \mathrm{INs}$ reduces oscillations in a broad frequency range (beta and gamma), suggesting that although $\mathrm{PV}^{+}$INs are thought to generate cortical gamma oscillation (Cardin et al., 2009), they also strongly modulate low-frequency band activity. Consistently, another study conducted by Veit et al. (2017) also demonstrated that context-dependent visually induced low-gamma activity in the $\mathrm{V} 1$ also requires $\mathrm{SST}^{+} \mathrm{INs}$. 


\section{OPTOGENETICS AND CHEMOGENETICS HIGHLIGHT CELL-TYPE SPECIFIC ROLE OF INs IN SOCIAL FEAR}

Although subtypes of cortical INs based on the expression of a single molecular marker may oversimplify the diversity of neural network organization (Kamigaki, 2019), this classification provides important opportunities to dissect cell-type-specific functions by recent innovative genetic tools. Optogenetics and chemogenetics are two of the most frequently used genetic techniques to specifically manipulate neuronal activity (Biselli et al., 2019). Optogenetics uses light-sensitive ion channels expressed in targeted cells allowing for neuronal depolarization or hyperpolarization with light illumination (Boyden et al., 2005), while chemogenetics uses designer receptors exclusively activated by designer drugs (DREADDs) expressed in targeted cells (Armbruster et al., 2007). The stimulatory DREADD hM3Dq (a modified human M3 muscarinic receptor) and the Gi-coupled hM4Di DREADD (a modified human M4 muscarinic receptor) have low affinity for the native ligand acetylcholine, but a high affinity for the synthetic ligand clozapine- $\mathrm{N}$-oxide (CNO). Intraperitoneally or intracranial $\mathrm{CNO}$ administration causes a downstream signaling cascade leading to either increased firing (for hM3Dq) or silencing (for hM4Di) of the targeted neurons, allowing for prolonged neuronal excitation or inhibition. Although $\mathrm{CNO}$ has been widely used as a ligand to activate muscarinic-based DREADDs, sluggish kinetics and metabolic liabilities have also existed. Notedly, a new high-affinity and selective agonist deschloroclozapine (DCZ) can also combine muscarinic-based DREADDs with utility in both mice and nonhuman primates for a variety of applications (Nagai et al., 2020). Except for muscarinic-based DREADD, other types of DREADDs were also developed for chemogenetic manipulations. For example, kappa opioid receptor (KOR)based DREADD is activated by Salvinorin B (SalB) allowing for inhibition of neuronal activity. Thus, co-expression of KORand M3-DREADDs allows remotely bidirectional modulation of activities of the same set of neurons with different ligands (Vardy et al., 2015).

Advances in tools for modulating or monitoring neuronal activity with cell-type specificity have expanded our understanding of the role of prefrontal INs in regulating social behaviors and dysfunctions. The development of genetically encoded calcium indicators, such as GCaMP (Chen et al., 2013), allows researchers to detect calcium transient in an individual neuron or a population of neurons (Ferguson and Gao, 2018). For example, by using fiber photometry to detect the overall activity of a distinct neuronal population, Selimbeyoglu et al. (2017) revealed that the activity of $\mathrm{mPFC} \mathrm{PV}^{+} \mathrm{INs}$ is increased in wild-type mice during social interactions with a conspecific compared to interactions with a novel object; however, in a genetic mouse model of autism, this difference was disappeared. Furthermore, either optogenetically increasing the activity of $\mathrm{PV}^{+}$INs or decreasing the activity of excitatory PNs in the mPFC rescues social impairment in this autism mouse model (Yizhar et al., 2011). Together, these findings suggest that elevated prefrontal cellular balance of excitation and inhibition (E/I balance) causes a profound impairment in social behaviors, and that compensation of mPFC inhibition can rescue social deficits. Similarly, Courtin et al. (2014) demonstrated that fear expression in conditioned auditory fear is causally linked to the phasic inhibition of $\mathrm{mPFC} \mathrm{PV}^{+}$INs.

One extremely useful technique termed "optogenetic tagging," which combines optogenetics with electrophysiological recording has been developed for in vivo identification of different neuronal subtypes at a single unit level (Zhao et al., 2011). This method is especially powerful for recording genetically identified subtypes of cortical GABAergic INs (Roux et al., 2014). Using this approach, we found that a majority of $\mathrm{mPFC} \mathrm{PV}^{+}$INs decrease their firing rate upon social confrontation in social fear-conditioned mice, whereas most $\mathrm{PV}^{+}$INs maintain their activity in unconditioned mice $(\mathrm{Xu}$ et al., 2019). The activity of another two types of mPFC INs, $\mathrm{SST}^{+}$, and $\mathrm{VIP}^{+}$INs was also monitored by fiber photometry in freely moving mice. It was found that the activity of $\mathrm{SST}^{+}$ INs is dramatically increased in social fear expression indicated by an increase in fluorescent signals when the mouse started each risk assessment behavior to approach a stimulus mouse. In contrast to $\mathrm{SST}^{+}$INs, the activity of $\mathrm{VIP}^{+}$INs is not altered during social fear expression (Xu et al., 2019). These observations clarified a significant association between the activities of distinct subtypes of mPFC INs with social fear expression. To further determine the causal relationship between mPFC INs activities and social fear expression, we employed a chemogenetic approach. After expression of hM3D on $\mathrm{PV}^{+}$ INs in the mPFC of social fear-conditioned mice, the social fear behavior is reduced upon $\mathrm{CNO}$ administration to activate those $\mathrm{PV}^{+}$INs. Conversely, chemogenetic inactivation of mPFC SST ${ }^{+}$ INs also reduced social fear expression (Xu et al., 2019). These findings demonstrate that neuronal activities of dmPFC INs were potently modified by aversive social experience and that the hyperactivity of mPFC SST ${ }^{+}$INs and hypoactivity of $\mathrm{PV}^{+} \mathrm{INs}$ are critical mechanisms of social fear.

\section{SST $^{+}$INS MEDIATED DISINHIBITION IN SOCIAL FEAR}

Besides feedforward inhibition and feedback inhibition, there is the third main type of "archetype circuit motifs" in the neural network, namely disinhibition (Letzkus et al., 2015; Tremblay et al., 2016; Möhler and Rudolph, 2017). Disinhibition is the removal of inhibition produced by one type of INs as a result of inhibitory action by another type of INs, and consequently enhances the activity of excitatory output neurons. It was firstly found in the hippocampus that a subpopulation of INs selectively innervates other GABAergic neurons, and this subpopulation includes calretinin-positive $\left(\mathrm{CR}^{+}\right)$INs (Gulyás et al., 1996) and VIP $^{+}$INs (Hajos et al., 1996). Such findings were then extended to the neocortex, where $\mathrm{CR}^{+}$INs often preferentially target other $\mathrm{CR}^{+}$INs and $\mathrm{CB}^{+}$INs in L2/3 (Defelipe et al., 1999; Gonchar and Burkhalter, 1999; Caputi et al., 2009). Growing studies using slice recordings revealed that $\mathrm{VIP}^{+}$INs have preferential connections with SST $^{+}$INs in diverse neocortices (Lee et al., 2013; 
Pfeffer et al., 2013; Pi et al., 2013). The VIP to SST disinhibitory connection is likely a general principle in the superficial layers of the neocortex (Tremblay et al., 2016). Furthermore, in L4 of the primary somatosensory cortex $\mathrm{SST}^{+}$INs preferentially target $\mathrm{PV}^{+}$INs, although their connection probability and synaptic strength are larger for PNs in the superficial layers (Xu et al., 2013). It seems that neocortical disinhibition of excitatory cells could be as powerful as direct inhibition (Tremblay et al., 2016).

All of the above observations were demonstrated in brain slices, it is critical to uncover whether this disinhibitory circuit operates in vivo, in particular under behavioral conditions. Here, we summarized well-known disinhibitory circuits in the literature, in particular for those with determined behavioral outcomes (Table 1). Recently, a couple of studies demonstrated that prefrontal $\mathrm{SST}^{+}$INs mediated disinhibition also plays a critical role in the control of fear-related behaviors in rodents. In one of our recent studies, three lines of observations support that it is $\mathrm{SST}^{+}$INs that inhibited $\mathrm{PV}^{+}$INs during social fear expression (Figure 2; Xu et al., 2019). First, there was a robust enhancement of the neuronal activity of $\mathrm{SST}^{+}$INs when the conditioned mouse approached the stimulus mouse, meanwhile, the activity of $\mathrm{PV}^{+}$INs was largely suppressed. Second, after chemogenetical inactivation of $\mathrm{SST}^{+}$INs, the activity reduction of $\mathrm{PV}^{+}$INs was significantly suppressed during the social approach. Third, the inactivation of $\mathrm{SST}^{+}$INs also decreased social fear behaviors in conditioned mice.

Consistently, using the auditory fear conditioning paradigm, an elegant study conducted by Cummings and Clem (2020) revealed that synaptic transmission, as well as auditory cue-evoked activity of prefrontal SST+ INs, are potentiated following cued fear learning. Besides, adopting diverse transgenic mice to independently tag $\mathrm{SST}^{+} \mathrm{INs}$ and $\mathrm{PV}^{+}$INs, they also provide direct electrophysiological evidence to show $\mathrm{SST}^{+}$ INs-evoked disinhibition in brain slices. The ratio of $\mathrm{SST}^{+}$INs elicited monosynaptic inhibition in $\mathrm{PV}^{+} \mathrm{INs}$ vs. surrounding PNs is strikingly increased in foot shock paired mice compared with that in the unpaired controls (Cummings and Clem, 2020), suggesting that fear conditioning shifts $\mathrm{SST}^{+}$INs to preferentially

TABLE 1 | Disinhibitory circuits and their physiological functions.

\begin{tabular}{|c|c|c|c|}
\hline Disinhibitory circuit & Brain region & Physiological function & Reference \\
\hline L1 INs-L2/3 VIP- PNs & V1 & Sharpening orientation by sound & Ibrahim et al. (2016) \\
\hline VIP-SST-PNs & $\mathrm{V}_{1}$ & $\begin{array}{l}\text { Enhancement of visual response by } \\
\text { locomotion/top-down modulation }\end{array}$ & Fu et al. (2014) and Zhang et al. (2014) \\
\hline CR-L2/3 CR/CB-PNs & V1/neocortex & NA & $\begin{array}{l}\text { Defelipe et al. (1999), Gonchar and Burkhalter } \\
\text { (1999) and Caputi et al. (2009) }\end{array}$ \\
\hline VIP-SST-PNs; & Visual cortex & NA & Pfeffer et al. (2013) and Karnani et al. (2016) \\
\hline \multicolumn{4}{|l|}{ SST-PV-PNs; } \\
\hline \multicolumn{4}{|l|}{ VIP-PV-PNs } \\
\hline VIP-SST-PNs & Auditory cortex & Auditory discrimination & Pi et al. (2013) \\
\hline L1 INs-L2/3 PV-PNs & Auditory cortex & Auditory associative fear learning & Letzkus et al. (2011, 2015) \\
\hline VIP-SST-PNS & $\mathrm{S} 1$ & $\begin{array}{l}\text { Enhancement of sensory processing by motor } \\
\text { activity }\end{array}$ & Lee et al. (2013) \\
\hline VIP-SST-PNs & S1 & Intracortical LTP & Williams and Holtmaat (2019) \\
\hline VIP-PV-PNs & S1 & NA & Dávid et al. (2007) \\
\hline L4 SST-PV-PNs & S1 & NA & Xu et al. (2013) \\
\hline L4 INs-L2/3 PV-L2/3 PNs & S1 & NA & Gainey et al. (2018) \\
\hline SST-PV-PNs & mPFC & Fear-related behaviors & Xu et al. (2019) and Cummings and Clem (2020) \\
\hline SST-PV-PNs & mPFC & Spatial working memory & Kim et al. (2016) \\
\hline SST-PV-PNs & Piriform cortex & NA & $\begin{array}{l}\text { Sturgill and Isaacson (2015) and Large et al. } \\
\text { (2016) }\end{array}$ \\
\hline VIP/CR-unknown-PNs & Hippocampal CA1 & Spatial Learning & Pardi et al. (2019) and Turi et al. (2019) \\
\hline VIP/CR-O/A INs-PNs & Hippocampal CA1 & NA & $\begin{array}{l}\text { Gulyás et al. (1996), Hajos et al. (1996), } \\
\text { Chamberland and Topolnik (2012), Tyan et al. } \\
\text { (2014) and Pelkey et al. (2017) }\end{array}$ \\
\hline VIP-PV-PNs & Hippocampal CA3 & Spatial learning; novel object recognition & Donato et al. (2013) \\
\hline PV-SST-PNs & BLA & Fear learning & Wolff et al. (2014) and Letzkus et al. (2015) \\
\hline VIP-PV/SST-PNs & BLA & Auditory associative fear learning & Krabbe et al. (2019) \\
\hline $\begin{array}{l}\text { CeL SST-CeL PKC- } \delta \text {-CeM output } \\
\text { neurons }\end{array}$ & CeA & Fear responses & $\begin{array}{l}\text { Ciocchi et al. (2010), Haubensak et al. } \\
\text { (2010) and Li et al. (2013) }\end{array}$ \\
\hline SST-CRF-output neurons; & $\mathrm{CeA}$ & Selection of active and passive fear responses & Fadok et al. (2017) \\
\hline \multicolumn{4}{|l|}{ CRF-SST-output neurons } \\
\hline Unknown INs-granule cells-mitral cells & Olfactory bulb & Odor discrimination & Nunes and Kuner (2015) \\
\hline NAcLat D1 MSNs-VTA INs-DA & VTA & Reward-related behavior & Yang et al. (2018) \\
\hline CEA INs-vIPAG INs-vIPAG & PAG & Motor response of freezing & Tovote et al. (2016) \\
\hline
\end{tabular}

BLA, basolateral amygdala; $C B$, calcium-binding proteins calbindin; $C e A$, central amygdala; CeM, medial part of central amygdala; CeL, lateral part of central amygdala; CR, calretinin; CRF, corticotropin-releasing factor; D1, D1-type DA receptors; DA, dopamine; LTP, long term potentiation; MSNs, medium spiny neurons; NAcLat, nucleus accumbens lateral shell; O/A, hippocampal CA1 stratum oriens/alveus; PAG, periaqueductal gray region; PKC- $\delta$, protein kinase $C-\delta$; PNs, principle neurons; V1, primary visual cortex; S1, primary somatosensory barrel cortex; VIPAG, ventrolateral periaqueductal gray region; VTA, ventral tegmental area. 


\section{Social fear expression}
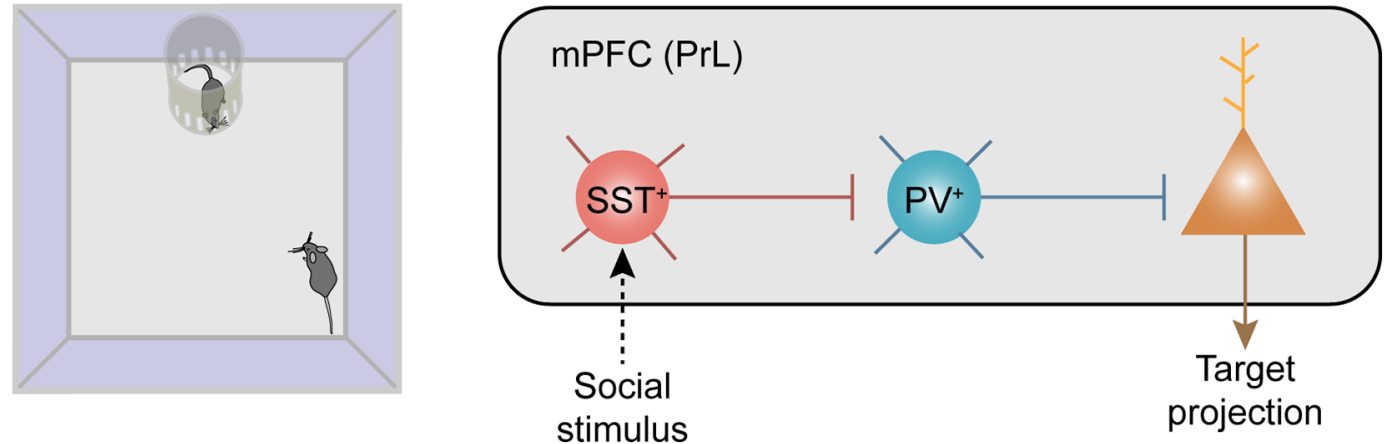

FIGURE 2 | Recruitment of neocortical disinhibitory microcircuits in fear-related behaviors. Disinhibitory connectivity in the medial prefrontal cortex (mPFC) during social fear expression. Left: the behavioral paradigm of the social fear expression. Right: social stimuli recruit SST ${ }^{+}$inhibitory interneurons (INs) which strongly inhibit $\mathrm{PV}^{+}$INs and trigger disinhibition of the projecting principal neurons (PNs) in the mPFC.

inhibit $\mathrm{PV}^{+}$INs and thereby produces disinhibition of PNs. This $\mathrm{SST}^{+}$INs-mediated disinhibition is also reflected in behavioral tests. For instance, concurrent optogenetic activation of $\mathrm{SST}^{+}$ INs and $\mathrm{PV}^{+}$INs abolished the fear-promoting effect of $\mathrm{SST}^{+}$INs (Cummings and Clem, 2020), implying that this potent disinhibitory control is important for fear expression. Additionally, it was previously found that in the auditory cortex a disinhibitory microcircuit mediated by L1 INs, which robustly inhibit $\mathrm{L} 2 / 3 \mathrm{PV}^{+}$INs and produce disinhibition of projecting PNs, plays a critical role in auditory fear learning (Letzkus et al., 2015).

It is known that distinct GABAergic neuronal populations in the $\mathrm{MPFC}$ receive differential long-range inputs from subcortical regions (Sun et al., 2019). In particular, $\mathrm{SST}^{+} \mathrm{INs}$ in the $\mathrm{mPFC}$ receive more cholinergic inputs compared with $\mathrm{PV}^{+}$or $\mathrm{VIP}^{+} \mathrm{INs}$, implying that acetylcholine release may preferentially drive $\mathrm{SST}^{+}$ INs (Sun et al., 2019). Using channelrhodopsin-assisted patching in awake mice, Muñoz et al. (2017) revealed that cholinergic modulation of SST ${ }^{+}$INs in the somatosensory cortex provides a major excitatory drive to these neurons during whisking. Interestingly, Letzkus et al. (2011) found that in the auditory cortex an aversive stimulus (i.e., a foot shock) strongly recruits cholinergic afferents from the basal forebrain. Taken together, it is likely that acetylcholine release during fear expression could potentially recruit the $\mathrm{SST}^{+}$INs-mediated disinhibitory microcircuit to reinforce $\mathrm{mPFC}$ output to drive social fear expression (Xu et al., 2019).

It is also important to determine downstream targets of the disinhibitory circuit mediated by $\mathrm{SST}^{+}$INs for top-down behavioral controls in social fear. Anatomically, the PNs in the mPFC send their axons to multiple cortical and subcortical brain regions that are involved in the regulation of fear expression. Besides PAG that has been shown in the regulation of social fear (Franklin et al., 2017), other downstream brain regions such as the amygdala (Ciocchi et al., 2010; Wolff et al., 2014), paraventricular nucleus of the thalamus (PVT; Do-Monte et al., 2015; Penzo et al., 2015) are also possible targets since they are well known for various forms of fear regulation. Indeed, by c-fos staining, Cummings and Clem (2020) found that following optogenetic activation of prefrontal SST ${ }^{+}$INs at $24 \mathrm{~h}$ after fear conditioning, a couple of remote downstream targets are identified, including BLA, PVT, lateral habenula, ventrolateral PAG and dorsomedial hypothalamus, suggesting that these brain regions are probably involved in this fear recruitment of $\mathrm{SST}^{+}$ INs-mediated disinhibition. Although PNs in the neocortex compose major output projections, GABAergic projections from the neocortex to subcortical regions have also been characterized recently (Lee et al., 2014). It was found that a subpopulation of $\mathrm{PV}^{+}$FS INs in the mPFC projects to the nucleus accumbens (NAc) which release GABA, and activation of this projection elicits avoidance behavior in a real-time place preference task, suggesting that this projection is involved in aversive signaling (Lee et al., 2014). However, this projection is not likely involved in the expression of conditioned social fear since the firing activities of $\mathrm{PV}^{+}$INs are indeed suppressed but not enhanced during social fear expression. Nevertheless, the exact brain networks downstream of mPFC outputs in control of social fear are to be dissected in future studies.

\section{TARGETING SST ${ }^{+}$INs TO CURE SOCIAL FEAR}

The aforementioned potent disinhibitory microcircuit in the $\mathrm{mPFC}$ opens a new possibility by targeting $\mathrm{SST}^{+}$INs to alleviate social fear behaviors. A couple of studies demonstrated that manipulation of prefrontal SST ${ }^{+}$INs can alter animals' defensive behaviors to fear response. For instance, we showed that chemogenetic inhibition of dmPFC $\mathrm{SST}^{+}$INs causes a direct reduction of social fear (Xu et al., 2019). Consistently, Cummings and Clem (2020) showed that optogenetic inhibition of SST ${ }^{+}$ INs in the dmPFC markedly reduces freezing in mice $24 \mathrm{~h}$ after cue-foot shock pairing. On the other hand, optogenetic activation of SST ${ }^{+}$INs de nova increases freezing in the absence of auditory cues. These observations suggest that inactivation of SST ${ }^{+}$INs in the dmPFC could serve as an effective treatment option to mitigate fear responses. 
The majority of antipsychotic drugs applied in the clinic to treat neuropsychiatric disorders have side effects due to their nonspecific actions outside the targeted brain regions. Besides, electric deep brain stimulation (DBS) or transcranial magnetic stimulation lacks cell-type specificity. A better understanding of brain node and network connectivity as well as advanced approaches like optogenetics and chemogenetics that can specifically manipulate targeted neuronal circuits could therefore be useful and of value to optimize therapeutic outcomes, although the invasiveness of these approaches limits their application in human beings (Jiang et al., 2017). Hopefully, progress in engineering will allow a new strategy of optogeneticsbased DBS (Ramirez-Zamora et al., 2019) to selectively inhibit $\mathrm{SST}^{+}$INs in the dmPFC with a high spatiotemporal resolution for future therapeutic purposes to treat social fear. For instance, using a potent fast red-shifted opsin ChRmine neuronal activations could be achieved by direct photostimulation above the surface of the intact skull (Chen et al., 2020). To avoid cranial surgery for viral delivery, systemic viral delivery of ChRmine was achieved to target dorsal raphe serotonergic neurons using engineered AAV to cross the blood-brain barrier, and activation of these neurons by transcranial light can promote social preference in a three-chamber test (Chen et al., 2020). Hence, a surgery-free and temporally-precise control of specific neural populations in animals is already doable. Currently, non-invasive optogenetics for neural manipulation at a depth of centimeters is not available for stimulating deep brain regions in humans (Chen and $\mathrm{McHugh}, 2020$ ). However, from a translational point of view, it is likely feasible to target prefrontal SST ${ }^{+}$INs given the fact that the cerebral cortex is the outmost structure of our brain.

\section{CONCLUDING REMARKS AND PERSPECTIVE}

Focused on mainly animal studies, we have reviewed recent research advances in social fear. We have presented evidence that both SFC and sub-chronic social defeat in mice can induce core behavioral symptoms of SAD without alterations in locomotion, general anxiety, and depressive-like behaviors. A cell-type-specific alteration in neuronal activities of $\mathrm{mPFC}$ neurons represents an important mechanism underlying social fear. Further, a potent disinhibitory control of surrounding PNs by prefrontal $\mathrm{SST}^{+}$INs plays a causal role in gating social fear behavior. In the future, identification of upstream inputs to the mPFC and also the exact downstream targets of the mPFC

\section{REFERENCES}

Abbas, A. I., Sundiang, M. J. M., Henoch, B., Morton, M. P., Bolkan, S. S., Park, A. J., et al. (2018). Somatostatin interneurons facilitate hippocampalprefrontal synchrony and prefrontal spatial encoding. Neuron 100, 926.e3-939.e3. doi: 10.1016/j.neuron.2018.09.029

Amodio, D. M., and Frith, C. D. (2006). Meeting of minds: the medial frontal cortex and social cognition. Nat. Rev. Neurosci. 7, 268-277. doi: $10.1038 / \mathrm{nrn} 1884$

Armbruster, B. N., Li, X., Pausch, M. H., Herlitze, S., and Roth, B. L. (2007). Evolving the lock to fit the key to create a family of $G$ protein-coupled will help to draw a more complete picture regarding the circuit mechanism underlying social fear.

Generally, social-behavioral decisions depend on the dynamic integration of sensory information and the animal's internal states (for review, see Chen and Hong, 2018). Correspondingly, for social fear expression, animals need to constantly combine both spatial and temporal sensory information with high-order memory representations originally acquired during fear conditioning. Integrating all this information with constantly changing internal states, animals eventually make a final decision and display appropriate defensive behaviors. The exact contribution of $\mathrm{SST}^{+}$INs and the $\mathrm{SST}^{+}$INs-mediated disinhibitory circuitry in each of these processes is another important question to be addressed.

Current evidence suggests that prefrontal $\mathrm{SST}^{+}$INs exert a potent disinhibitory control over PNs during fear-related behaviors that are not necessarily specific in the social domain. Interestingly, it is recently reported that prefrontal SST ${ }^{+}$INs are involved in discriminating the affective states of conspecifics in mice (Scheggia et al., 2020). Therefore, it is still possible that there exists a subpopulation of $\mathrm{SST}^{+}$INs and their network are somehow wired specifically for processing social related information due to their distinct sensory inputs. Future studies using in vivo two-photo calcium imaging or microendoscope will be helpful to address this issue.

\section{AUTHOR CONTRIBUTIONS}

JW, YT, L-HZ and HX made a direct contribution to the work and approved it for publication. All authors contributed to the article and approved the submitted version.

\section{FUNDING}

This study was supported by grants from the National Natural Science Foundation of China (32071005, 31471025, and 91432110) to HX and JW (31900729); the National Key R\&D Program of China (2016YFA0501000); the Zhejiang Provincial Natural Science Foundation of China (LR17H090002); the Chinese Ministry of Education Project 111 Program (B13026); and the Non-profit Central Research Institute Fund of Chinese Academy of Medical Sciences (2017PT31038 and 2018PT31041) to HX. This study was also supported by the Fundamental Research Funds for the Central Universities.

receptors potently activated by an inert ligand. Proc. Natl. Acad. Sci. U S A 104 5163-5168. doi: 10.1073/pnas.0700293104

American Psychiatric Publishing. (2013). Diagnostic and Statistical Manual of Mental Disorders (DSM-5). Arlington: American Psychiatric Publishing .

Biselli, T., Lange, S. S., Sablottny, L., Steffen, J., and Walther, A. (2019). Optogenetic and chemogenetic insights into the neurocircuitry of depression-like behaviour: a systematic review. Eur. J. Neurosci. doi: 10.1111/ejn.14603. [Epub ahead of print].

Blanco, C., Antia, S. X., and Liebowitz, M. R. (2002). Pharmacotherapy of social anxiety disorder. Biol. Psychiatry 51, 109-120. doi: 10.1016/s00063223(01)01294-x 
Boyden, E. S., Zhang, F., Bamberg, E., Nagel, G., and Deisseroth, K. (2005). Millisecond-timescale, genetically targeted optical control of neural activity. Nat. Neurosci. 8, 1263-1268. doi: 10.1038/nn1525

Buff, C., Brinkmann, L., Neumeister, P., Feldker, K., Heitmann, C., Gathmann, B., et al. (2016). Specifically altered brain responses to threat in generalized anxiety disorder relative to social anxiety disorder and panic disorder. Neuroimage Clin. 12, 698-706. doi: 10.1016/j.nicl.2016.09.023

Burgos-Robles, A., Vidal-Gonzalez, I., and Quirk, G. J. (2009). Sustained conditioned responses in prelimbic prefrontal neurons are correlated with fear expression and extinction failure. J. Neurosci. 29, 8474-8482. doi: 10.1523/JNEUROSCI.0378-09.2009

Caputi, A., Rozov, A., Blatow, M., and Monyer, H. (2009). Two calretinin-positive GABAergic cell types in layer $2 / 3$ of the mouse neocortex provide different forms of inhibition. Cereb. Cortex 19, 1345-1359. doi: 10.1093/cercor/bhn175

Cardin, J. A., Carlén, M., Meletis, K., Knoblich, U., Zhang, F., Deisseroth, K., et al. (2009). Driving fast-spiking cells induces gamma rhythm and controls sensory responses. Nature 459, 663-667. doi: 10.1038/nature08002

Chang, Y.-H., Liu, S.-W., and Chang, C.-H. (2018). Pharmacological activation of the lateral orbitofrontal cortex on regulation of learned fear and extinction. Neurobiol. Learn. Mem. 148, 30-37. doi: 10.1016/j.nlm.2017. 12.011

Chamberland, S., and Topolnik, L. (2012). Inhibitory control of hippocampal inhibitory neurons. Front. Neurosci. 6:165. doi: 10.3389/fnins.2012.00165

Chen, R., Gore, F., Nguyen, Q. A., Ramakrishnan, C., Patel, S., Kim, S. H., et al. (2020). Deep brain optogenetics without intracranial surgery. Nat. Biotechnol. doi: 10.1038/s41587-020-0679-9 [Epub ahead of print].

Chen, P., and Hong, W. (2018). Neural circuit mechanisms of social behavior. Neuron 98, 16-30. doi: 10.1016/j.neuron.2018.02.026

Chen, S., and McHugh, T. J. (2020). Further-reaching optogenetics. Nat. Biomed. Eng. 4, 1028-1029. doi: 10.1038/s41551-020-00648-y

Chen, T.-W., Wardill, T.-J., Sun, Y., Pulver, S. R., Renninger, S. L., Baohan, A., et al. (2013). Ultrasensitive fluorescent proteins for imaging neuronal activity. Nature 499, 295-300. doi: 10.1038/nature12354

Chen, G., Zhang, Y., Li, X., Zhao, X., Ye, Q., Lin, Y., et al. (2017). Distinct inhibitory circuits orchestrate cortical beta and gamma band oscillations. Neuron 96, 1403.e6-1418.e6. doi: 10.1016/j.neuron.2017.11.033

Ciocchi, S., Herry, C., Grenier, F., Wolff, S. B., Letzkus, J. J., Vlachos, I., et al. (2010). Encoding of conditioned fear in central amygdala inhibitory circuits. Nature 468, 277-282. doi: 10.1038/nature09559

Courtin, J., Chaudun, F., Rozeske, R. R., Karalis, N., Gonzalez-Campo, C., Wurtz, H., et al. (2014). Prefrontal parvalbumin interneurons shape neuronal activity to drive fear expression. Nature 505, 92-96. doi: 10.1038/nature12755

Cummings, K. A., and Clem, R. L. (2020). Prefrontal somatostatin interneurons encode fear memory. Nat. Neurosci. 23, 61-74. doi: 10.1038/s41593-019 $-0552-7$

Dalley, J. W., Cardinal, R. N., and Robbins, T. W. (2004). Prefrontal executive and cognitive functions in rodents: neural and neurochemical substrates. Neurosci. Biobehav. Rev. 28, 771-784. doi: 10.1016/j.neubiorev.2004.09.006

Dávid, C., Schleicher, A., Zuschratter, W., and Staiger, J. F. (2007). The innervation of parvalbumin-containing interneurons by VIP-immunopositive interneurons in the primary somatosensory cortex of the adult rat. Eur. J. Neurosci. 25, 2329-2340. doi: 10.1111/j.1460-9568.2007.05496.x

Defelipe, J., González-Albo, M. C., Del Río, M. R., and Elston, G. N. (1999). Distribution and patterns of connectivity of interneurons containing calbindin, calretinin, and parvalbumin in visual areas of the occipital and temporal lobes of the macaque monkey. J. Comp. Neurol. 412, 515-526. doi: 10.1002/(sici)1096-9861(19990927)412:3<515::aid-cne10>3.0.co;2-1

Do-Monte, F. H., Quinones-Laracuente, K., and Quirk, G. J. (2015). A temporal shift in the circuits mediating retrieval of fear memory. Nature 519, 460-463. doi: 10.1038/nature 14030

Donato, F., Rompani, S. B., and Caroni, P. (2013). Parvalbumin-expressing basket-cell network plasticity induced by experience regulates adult learning. Nature 504, 272-276. doi: 10.1038/nature12866

Doruyter, A. G., Dupont, P., Stein, D. J., Lochner, C., and Warwick, J. M. (2018). Nuclear neuroimaging in social anxiety disorder: a review. J. Nucl. Med. 59, 1794-1800. doi: 10.2967/jnumed.118.212795

Dos Santos, R. G., de Lima Osório, F., Martin-Santos, R., Zuardi, A. W., Hallak, J. E. C., and Crippa, J. A. S. (2019). Modulation of the endocannabinoid and oxytocinergic systems as a potential treatment approach for social anxiety disorder. CNS Drugs 33, 1031-1038. doi: 10.1007/s40263-019-00669-5

Etkin, A., Egner, T., and Kalisch, R. (2011). Emotional processing in anterior cingulate and medial prefrontal cortex. Trends Cogn. Sci. 15, 85-93. doi: 10.1016/j.tics.2010.11.004

Fadok, J. P., Krabbe, S., Markovic, M., Courtin, J., Xu, C., Massi, L., et al. (2017). A competitive inhibitory circuit for selection of active and passive fear responses. Nature 542, 96-100. doi: 10.1038/nature21047

Ferguson, B. R., and Gao, W.-J. (2018). PV interneurons: critical regulators of E/I balance for prefrontal cortex-dependent behavior and psychiatric disorders. Front. Neural Circuits 12:37. doi: 10.3389/fncir.2018.00037

Figel, B., Brinkmann, L., Buff, C., Heitmann, C. Y., Hofmann, D., Bruchmann, M., et al. (2019). Phasic amygdala and BNST activation during the anticipation of temporally unpredictable social observation in social anxiety disorder patients. Neuroimage Clin. 22:101735. doi: 10.1016/j.nicl.2019.101735

Franklin, T. B., Silva, B. A., Perova, Z., Marrone, L., Masferrer, M. E., Zhan, Y., et al. (2017). Prefrontal cortical control of a brainstem social behavior circuit. Nat. Neurosci. 20, 260-270. doi: 10.1038/nn.4470

Frick, A., Engman, J., Alaie, I., Bjorkstrand, J., Gingnell, M., Larsson, E. M., et al. (2020). Neuroimaging, genetic, clinical, and demographic predictors of treatment response in patients with social anxiety disorder. J. Affect. Disord. 261, 230-237. doi: 10.1016/j.jad.2019.10.027

Fu, Y., Tucciarone, J. M., Espinosa, J. S., Sheng, N., Darcy, D. P., Nicoll, R. A., et al. (2014). A cortical circuit for gain control by behavioral state. Cell 156, 1139-1152. doi: 10.1016/j.cell.2014.01.050

Gainey, M. A., Aman, J. W., and Feldman, D. E. (2018). Rapid disinhibition by adjustment of PV intrinsic excitability during whisker map plasticity in mouse S1. J. Neurosci. 38, 4749-4761. doi: 10.1523/JNEUROSCI.3628-17.2018

Golden, S. A., Covington, H. E. III., Berton, O., and Russo, S. J. (2011). A standardized protocol for repeated social defeat stress in mice. Nat. Protoc. 6, 1183-1191. doi: 10.1038/nprot.2011.361

Gonchar, Y., and Burkhalter, A. (1999). Connectivity of GABAergic calretininimmunoreactive neurons in rat primary visual cortex. Cereb. Cortex 9, 683-696. doi: $10.1093 /$ cercor/9.7.683

Goodson, J. L. (2005). The vertebrate social behavior network: evolutionary themes and variations. Horm. Behav. 48, 11-22. doi: 10.1016/j.yhbeh.2005.02.003

Gulyás, A. I., Hájos, N., and Freund, T. F. (1996). Interneurons containing calretinin are specialized to control other interneurons in the rat hippocampus. J. Neurosci. 16, 3397-3411. doi: 10.1523/JNEUROSCI.16-10-03397.1996

Hajos, N., Acsady, L., and Freund, T. F. (1996). Target selectivity and neurochemical characteristics of VIP-immunoreactive interneurons in the rat dentate gyrus. Eur. J. Neurosci. 8, 1415-1431. doi: 10.1111/j.1460-9568.1996. tb01604. $x$

Haller, J., and Bakos, N. (2002). Stress-induced social avoidance: a new model of stress-induced anxiety? Physiol. Behav. 77, 327-332. doi: 10.1016/s00319384(02)00860-0

Hattori, R., Kuchibhotla, K. V., Froemke, R. C., and Komiyama, T. (2017). Functions and dysfunctions of neocortical inhibitory neuron subtypes. Nat. Neurosci. 20, 1199-1208. doi: 10.1038/nn.4619

Haubensak, W., Kunwar, P. S., Cai, H., Ciocchi, S., Wall, N. R., Ponnusamy, R., et al. (2010). Genetic dissection of an amygdala microcircuit that gates conditioned fear. Nature 468, 270-276. doi: 10.1038/nature09553

Hermes, G., Li, N., Duman, C., and Duman, R. (2011). Post-weaning chronic social isolation produces profound behavioral dysregulation with decreases in prefrontal cortex synaptic-associated protein expression in female rats. Physiol. Behav. 104, 354-359. doi: 10.1016/j.physbeh.2010.12.019

Hsieh, H.-T., and Chang, C.-H. (2020). Activation of medial orbitofrontal cortex abolishes fear extinction and interferes with fear expression in rats. Neurobiol. Learn. Mem. 169:107170. doi: 10.1016/j.nlm.2020.107170

Huhman, K. L. (2006). Social conflict models: can they inform us about human psychopathology? Horm. Behav. 50, 640-646. doi: 10.1016/j.yhbeh.2006.06.022

Ibrahim, L. A., Mesik, L., Ji, X. Y., Fang, Q., Li, H. F., Li, Y. T., et al. (2016). Crossmodality sharpening of visual cortical processing through layer-1-mediated inhibition and disinhibition. Neuron 89, 1031-1045. doi: 10.1016/j.neuron. 2016.01.027

Jiang, J., Cui, H., and Rahmouni, K. (2017). Optogenetics and pharmacogenetics: principles and applications. Am. J. Physiol. Regul. Integr. Comp. Physiol. 313, R633-R645. doi: 10.1152/ajpregu.00091.2017 
Jones, C., Barrera, I., Brothers, S., Ring, R., and Wahlestedt, C. (2017). Oxytocin and social functioning. Dialogues Clin. Neurosci. 19, 193-201. doi: 10.31887/DCNS.2017.19.2/cjones

Kamigaki, T. (2019). Prefrontal circuit organization for executive control. Neurosci. Res. 140, 23-36. doi: 10.1016/j.neures.2018.08.017

Karalis, N., Dejean, C., Chaudun, F., Khoder, S., Rozeske, R. R., Wurtz, H., et al. (2016). 4-Hz oscillations synchronize prefrontal-amygdala circuits during fear behavior. Nat. Neurosci. 19, 605-612. doi: 10.1038/nn.4251

Karnani, M. M., Jackson, J., Ayzenshtat, I., Hamzehei Sichani, A., Manoocheri, K., Kim, S., et al. (2016). Opening holes in the blanket of inhibition: localized lateral disinhibition by VIP interneurons. J. Neurosci. 36, 3471-3480. doi: 10.1523/JNEUROSCI.3646-15.2016

Kawaguchi, Y., and Kubota, Y. (1997). GABAergic cell subtypes and their synaptic connections in rat frontal cortex. Cereb. Cortex 7, 476-486. doi: 10.1093/cercor/7.6.476

Kawashima, C., Tanaka, Y., Inoue, A., Nakanishi, M., Okamoto, K., Maruyama, Y., et al. (2016). Hyperfunction of left lateral prefrontal cortex and automatic thoughts in social anxiety disorder: a near-infrared spectroscopy study. J. Affect. Disord. 206, 256-260. doi: 10.1016/j.jad.2016.07.028

Kessler, R. C., Berglund, P., Demler, O., Jin, R., Merikangas, K. R., and Walters, E. E. (2005a). Lifetime prevalence and age-of-onset distributions of DSM-IV disorders in the National Comorbidity Survey Replication. Arch. Gen. Psychiatry 62, 593-602. doi: 10.1001/archpsyc.62.6.593

Kessler, R. C., Chiu, W. T., Demler, O., Merikangas, K. R., and Walters, E. E. (2005b). Prevalence, severity, and comorbidity of 12-month DSM-IV disorders in the National Comorbidity Survey Replication. Arch. Gen. Psychiatry 62, 617-627. doi: 10.1001/archpsyc.62.6.617

Kim, D., Jeong, H., Lee, J., Ghim, J. W., Her, E. S., Lee, S. H., et al. (2016). Distinct roles of parvalbumin- and somatostatin-expressing interneurons in working memory. Neuron 92, 902-915. doi: 10.1016/j.neuron.2016.09.023

Ko, J. (2017). Neuroanatomical substrates of rodent social behavior: the medial prefrontal cortex and its projection patterns. Front. Neural Circuits 11:41. doi: 10.3389/fncir.2017.00041

Krabbe, S., Paradiso, E., d'Aquin, S., Bitterman, Y., Courtin, J., Xu, C., et al. (2019). Adaptive disinhibitory gating by VIP interneurons permits associative learning. Nat. Neurosci. 22, 1834-1843. doi: 10.1038/s41593-019-0508-y

Kraus, J., Frick, A., Fischer, H., Howner, K., Fredrikson, M., and Furmark, T. (2018). Amygdala reactivity and connectivity during social and non-social aversive stimulation in social anxiety disorder. Psychiatry Res. Neuroimaging 280, 56-61. doi: 10.1016/j.pscychresns.2018.08.012

Large, A. M., Kunz, N. A., Mielo, S. L., and Oswald, A. M. (2016). Inhibition by somatostatin interneurons in olfactory cortex. Front. Neural Circuits 10:62. doi: 10.3389/fncir.2016.00062

Lee, S., Kruglikov, I., Huang, Z. J., Fishell, G., and Rudy, B. (2013). A disinhibitory circuit mediates motor integration in the somatosensory cortex. Nat. Neurosci. 16, 1662-1670. doi: 10.1038/nn.3544

Lee, A. T., Vogt, D., Rubenstein, J. L., and Sohal, V. S. (2014). A class of GABAergic neurons in the prefrontal cortex sends long-range projections to the nucleus accumbens and elicits acute avoidance behavior. J. Neurosci. 34, 11519-11525. doi: 10.1523/JNEUROSCI.1157-14.2014

Leichsenring, F., and Leweke, F. (2017). Social anxiety disorder. N. Engl. J. Med. 376, 2255-2264. doi: 10.1056/NEJMcp1614701

Letzkus, J. J., Wolff, S. B., and Lüthi, A. (2015). Disinhibition, a circuit mechanism for associative learning and memory. Neuron 88, 264-276. doi: 10.1016/j. neuron.2015.09.024

Letzkus, J. J., Wolff, S. B., Meyer, E. M., Tovote, P., Courtin, J., Herry, C., et al. (2011). A disinhibitory microcircuit for associative fear learning in the auditory cortex. Nature 480, 331-335. doi: 10.1038/nature10674

Li, H., Penzo, M. A., Taniguchi, H., Kopec, C. D., Huang, Z. J., and Li, B. (2013). Experience-dependent modification of a central amygdala fear circuit. Nat Neurosci 16, 332-339. doi: 10.1038/nn.3322

Möhler, H., and Rudolph, U. (2017). Disinhibition, an emerging pharmacology of learning and memory. F1000Res. 6:F1000. doi: 10.12688/f1000research.9947.1

Muñoz, W., Tremblay, R., Levenstein, D., and Rudy, B. (2017). Layer-specific modulation of neocortical dendritic inhibition during active wakefulness. Science 355, 954-959. doi: 10.1126/science.aag2599

Nagai, Y., Miyakawa, N., Takuwa, H., Hori, Y., Oyama, K., Ji, B., et al. (2020). Deschloroclozapine, a potent and selective chemogenetic actuator enables rapid neuronal and behavioral modulations in mice and monkeys. Nat. Neurosci. 23 , 1157-1167. doi: 10.1038/s41593-020-0661-3

Nees, F., Witt, S. H., and Flor, H. (2018). Neurogenetic approaches to stress and fear in humans as pathophysiological mechanisms for posttraumatic stress disorder. Biol. Psychiatry 83, 810-820. doi: 10.1016/j.biopsych.2017.12.015

Niwa, M., Matsumoto, Y., Mouri, A., Ozaki, N., and Nabeshima, T. (2011). Vulnerability in early life to changes in the rearing environment plays a crucial role in the aetiopathology of psychiatric disorders. Int. J. Neuropsychopharmacol. 14, 459-477. doi: 10.1017/S1461145710001239

Nunes, D., and Kuner, T. (2015). Disinhibition of olfactory bulb granule cells accelerates odour discrimination in mice. Nat. Commun. 6:8950. doi: 10.1038/ncomms 9950

Pardi, M. B., Abs, E., and Letzkus, J. J. (2019). Disinhibition goes spatial. Neuron 101, 994-996. doi: 10.1016/j.neuron.2019.03.006

Paré, D., and Collins, D. R. (2000). Neuronal correlates of fear in the lateral amygdala: multiple extracellular recordings in conscious cats. J. Neurosci. 20, 2701-2710. doi: 10.1523/JNEUROSCI.20-07-02701.2000

Pelkey, K. A., Chittajallu, R., Craig, M. T., Tricoire, L., Wester, J. C., and McBain, C. J. (2017). Hippocampal GABAergic inhibitory interneurons. Physiol. Rev. 97, 1619-1747. doi: 10.1152/physrev.00007.2017

Penzo, M. A., Robert, V., Tucciarone, J., De Bundel, D., Wang, M., Van Aelst, L., et al. (2015). The paraventricular thalamus controls a central amygdala fear circuit. Nature 519, 455-459. doi: 10.1038/nature13978

Pfeffer, C. K., Xue, M., He, M., Huang, Z. J., and Scanziani, M. (2013). Inhibition of inhibition in visual cortex: the logic of connections between molecularly distinct interneurons. Nat. Neurosci. 16, 1068-1076. doi: 10.1038/nn.3446

Pi, H.-J., Hangya, B., Kvitsiani, D., Sanders, J. I., Huang, Z. J., and Kepecs, A. (2013). Cortical interneurons that specialize in disinhibitory control. Nature 503, 521-524. doi: 10.1038/nature 12676

Quirk, G. J., Garcia, R., and González-Lima, F. (2006). Prefrontal mechanisms in extinction of conditioned fear. Biol. Psychiatry 60, 337-343. doi: 10.1016/j. biopsych.2006.03.010

Quirk, G. J., Repa, C., and LeDoux, J. E. (1995). Fear conditioning enhances shortlatency auditory responses of lateral amygdala neurons: parallel recordings in the freely behaving rat. Neuron 15, 1029-1039. doi: 10.1016/08966273(95)90092-6

Ramirez-Zamora, A., Giordano, J., Boyden, E. S., Gradinaru, V., Gunduz, A., Starr, P. A., et al. (2019). Proceedings of the sixth deep brain stimulation think tank modulation of brain networks and application of advanced neuroimaging, neurophysiology, and optogenetics. Front. Neurosci. 13:936. doi: 10.3389/fnins. 2019.00936

Rodriguez-Romaguera, J., Do-Monte, F. H., Tanimura, Y., Quirk, G. J., and Haber, S. N. (2015). Enhancement of fear extinction with deep brain stimulation: evidence for medial orbitofrontal involvement. Neuropsychopharmacology 40, 1726-1733. doi: 10.1038/npp.2015.20

Roux, L., Stark, E., Sjulson, L., and Buzsaki, G. (2014). in vivo optogenetic identification and manipulation of GABAergic interneuron subtypes. Curr. Opin. Neurobiol. 26, 88-95. doi: 10.1016/j.conb.2013.12.013

Rubenstein, J. L., and Merzenich, M. M. (2003). Model of autism: increased ratio of excitation/inhibition in key neural systems. Genes Brain Behav. 2, 255-267. doi: 10.1034/j.1601-183x.2003.00037.x

Rudy, B., Fishell, G., Lee, S., and Hjerling-Leffler, J. (2011). Three groups of interneurons account for nearly $100 \%$ of neocortical GABAergic neurons. Dev. Neurobiol. 71, 45-61. doi: 10.1002/dneu.20853

Sarlitto, M. C., Foilb, A. R., and Christianson, J. P. (2018). Inactivation of the ventrolateral orbitofrontal cortex impairs flexible use of safety signals. Neuroscience 379, 350-358. doi: 10.1016/j.neuroscience.2018.03.037

Scheggia, D., Managò, F., Maltese, F., Bruni, S., Nigro, M., Dautan, D., et al. (2020). Somatostatin interneurons in the prefrontal cortex control affective state discrimination in mice. Nat. Neurosci. 23, 47-60. doi: 10.1038/s41593019-0551-8

Selimbeyoglu, A., Kim, C. K., Inoue, M., Lee, S. Y., Hong, A. S. O., Kauvar, I., et al. (2017). Modulation of prefrontal cortex excitation/inhibition balance rescues social behavior in CNTNAP2-deficient mice. Sci. Transl. Med. 9:eaah6733. doi: 10.1126/scitranslmed.aah6733

Sohal, V. S., and Rubenstein, J. L. R. (2019). Excitation-inhibition balance as a framework for investigating mechanisms in neuropsychiatric disorders. Mol. Psychiatry 24, 1248-1257. doi: 10.1038/s41380-019-0426-0 
Stein, M. B., and Stein, D. J. (2008). Social anxiety disorder. Lancet 371, 1115-1125. doi: 10.1016/S0140-6736(08)60488-2

Sturgill, J. F., and Isaacson, J. S. (2015). Somatostatin cells regulate sensory response fidelity via subtractive inhibition in olfactory cortex. Nat. Neurosci. 18, 531-535. doi: 10.1038/nn.3971

Sun, Q., Li, X., Ren, M., Zhao, M., Zhong, Q., Ren, Y., et al. (2019). A whole-brain map of long-range inputs to GABAergic interneurons in the mouse medial prefrontal cortex. Nat. Neurosci. 22, 1357-1370. doi: 10.1038/s41593-019 $-0429-9$

Toth, I., and Neumann, I. D. (2013). Animal models of social avoidance and social fear. Cell Tissue Res. 354, 107-118. doi: 10.1007/s00441-013-1636-4

Toth, I., Neumann, I. D., and Slattery, D. A. (2012). Social fear conditioning: a novel and specific animal model to study social anxiety disorder. Neuropsychopharmacology 37, 1433-1443. doi: 10.1038/npp.2011.329

Toth, I., Neumann, I. D., and Slattery, D. A. (2013). Social fear conditioning as an animal model of social anxiety disorder. Curr. Protoc. Neurosci. Chapter 9:Unit 9.42. doi: 10.1002/0471142301.ns0942s63

Tovote, P., Esposito, M. S., Botta, P., Chaudun, F., Fadok, J. P., Markovic, M., et al. (2016). Midbrain circuits for defensive behaviour. Nature 534, 206-212. doi: $10.1038 /$ nature 17996

Tremblay, R., Lee, S., and Rudy, B. (2016). GABAergic interneurons in the neocortex: from cellular properties to circuits. Neuron 91, 260-292. doi: $10.1016 /$ j.neuron.2016.06.033

Turi, G. F., Li, W. K., Chavlis, S., Pandi, I., O'Hare, J., Priestley, J. B., et al. (2019). Vasoactive intestinal polypeptide-expressing interneurons in the hippocampus support goal-oriented spatial learning. Neuron 101, 1150.e8-1165.e8. doi: 10.1016/j.neuron.2019.01.009

Tyan, L., Chamberland, S., Magnin, E., Camire, O., Francavilla, R., David, L. S., et al. (2014). Dendritic inhibition provided by interneuron-specific cells controls the firing rate and timing of the hippocampal feedback inhibitory circuitry. J. Neurosci. 34, 4534-4547. doi: 10.1523/JNEUROSCI.381313.2014

Vardy, E., Robinson, J. E., Li, C., Olsen, R. H. J., DiBerto, J. F., Giguere, P. M., et al. (2015). A new DREADD facilitates the multiplexed chemogenetic interrogation of behavior. Neuron 86, 936-946. doi: 10.1016/j.neuron.2015. 03.065

Veit, J., Hakim, R., Jadi, M. P., Sejnowski, T. J., and Adesnik, H. (2017). Cortical gamma band synchronization through somatostatin interneurons. Nat. Neurosci. 20, 951-959. doi: 10.1038/nn.4562

Wang, Q., Wang, Q., Song, X.-L., Jiang, Q., Wu, Y.-J., Li, Y., et al. (2018). Fear extinction requires ASIC1a-dependent regulation of hippocampal-prefrontal correlates. Sci. Adv. 4:eaau3075. doi: 10.1126/sciadv.aau3075
Williams, L. E., and Holtmaat, A. (2019). Higher-order thalamocortical inputs gate synaptic long-term potentiation via disinhibition. Neuron 101, 91.e4-102.e4. doi: 10.1016/j.neuron.2018.10.049

Wolff, S. B., Gründemann, J., Tovote, P., Krabbe, S., Jacobson, G. A., Muller, C., et al. (2014). Amygdala interneuron subtypes control fear learning through disinhibition. Nature 509, 453-458. doi: 10.1038/nature13258

Xu, H., Jeong, H.-Y., Tremblay, R., and Rudy, B. (2013). Neocortical somatostatinexpressing GABAergic interneurons disinhibit the thalamorecipient layer 4. Neuron 77, 155-167. doi: 10.1016/j.neuron.2012.11.004

Xu, H., Liu, L., Tian, Y., Wang, J., Li, J., Zheng, J., et al. (2019). A disinhibitory microcircuit mediates conditioned social fear in the prefrontal cortex. Neuron 102, 668.e5-682.e5. doi: 10.1016/j.neuron.2019.02.026

Yang, H., de Jong, J. W., Tak, Y., Peck, J., Bateup, H. S., and Lammel, S. (2018). Nucleus accumbens subnuclei regulate motivated behavior via direct inhibition and disinhibition of VTA dopamine subpopulations. Neuron 97, 434.e4-449.e4. doi: 10.1016/j.neuron.2017.12.022

Yizhar, O., Fenno, L. E., Prigge, M., Schneider, F., Davidson, T. J., O'Shea, D. J., et al. (2011). Neocortical excitation/inhibition balance in information processing and social dysfunction. Nature 477, 171-178. doi: 10.1038/nature10360

Zhang, S., Xu, M., Kamigaki, T., Hoang Do, J. P., Chang, W. C., Jenvay, S., et al. (2014). Selective attention. Long-range and local circuits for top-down modulation of visual cortex processing. Science 345, 660-665. doi: 10.1126/science. 1254126

Zhao, S., Ting, J. T., Atallah, H. E., Qiu, L., Tan, J., Gloss, B., et al. (2011). Cell type-specific channelrhodopsin-2 transgenic mice for optogenetic dissection of neural circuitry function. Nat. Methods 8, 745-752. doi: 10.1038/nmeth.1668

Zhu, H., Qiu, C., Meng, Y., Yuan, M., Zhang, Y., Ren, Z., et al. (2017). Altered topological properties of brain networks in social anxiety disorder: a restingstate functional MRI study. Sci. Rep. 7:43089. doi: 10.1038/srep43089

Conflict of Interest: The authors declare that the research was conducted in the absence of any commercial or financial relationships that could be construed as a potential conflict of interest.

Copyright () 2020 Wang, Tian, Zeng and Xu. This is an open-access article distributed under the terms of the Creative Commons Attribution License (CC BY). The use, distribution or reproduction in other forums is permitted, provided the original author(s) and the copyright owner(s) are credited and that the original publication in this journal is cited, in accordance with accepted academic practice. No use, distribution or reproduction is permitted which does not comply with these terms. 